\title{
PREDICTIVE ACCURACY OF VARIOUS IOL POWER CALCULATION FORMULAE IN HIGH AXIAL MYOPIA: A PROSPECTIVE COMPARATIVE STUDY
}

\author{
Anita Thakur', Nutan Saxena², A. M. Jain³, Ruchika Agarwal ${ }^{4}$ \\ ${ }^{1}$ Associate Professor, Department of Ophthalmology, Rama Medical College Hospital and Research Centre, Mandhana, Kanpur. \\ ${ }^{2}$ Assistant Professor, Department of Ophthalmology, Rama Medical College Hospital and Research Centre, Mandhana, Kanpur. \\ ${ }^{3}$ Professor, Department of Ophthalmology, Rama Medical College Hospital and Research Centre, Mandhana, Kanpur. \\ ${ }^{4}$ Assistant Professor, Department of Ophthalmology, Rama Medical College Hospital and Research Centre, Mandhana, Kanpur.
}

ABSTRACT

\section{PURPOSE}

To compare the accuracy of Intraocular Lens (IOL) power calculation formulae in high axial myopia.

\section{MATERIAL AND METHODS}

27 eyes of 22 patients with axial length between $26 \mathrm{~mm}$ to $30 \mathrm{~mm}$ were studied. The eyes were divided in to two groups, Group 1 with AL 26-28mm consisting of 23 eyes and Group 2 with AL 28-30mm consisting of four eyes. The predictive accuracy of four formulae SRK-T, Hoffer Q, Haigis and Holladay 2 were evaluated and compared. The statistical analysis was carried out with SPSS Software 21.0 version with $P$ value $>0.05$ considered significant.

\section{RESULTS}

The predictive capability within \pm 1 D of these formulae in Group 1 is $88 \%$ with SRK-T, $87 \%$ with Hoffer Q, 88\% with Haigis and $91 \%$ with Holladay 2 and within $\pm 0.5 \mathrm{D}$ is $61 \%, 61 \%, 69 \%$ and $73 \%$ respectively. In Group 2 which consisted of 4 eyes with AL between $28-30 \mathrm{~mm}$ the results were $83 \%, 83 \%, 84 \%, 90 \%, 59 \%, 61 \%, 70 \%, 71 \%$ respectively.

\section{CONCLUSION}

The performance of SRK-T, Hoffer $Q$ and Haigis was comparable for target refraction of $\pm 1.0 \mathrm{D}$, whereas Haigis and Holladay 2 gave relatively better results for target refraction of $\pm 0.5 \mathrm{D}$ for Group 1 and Haigis and Holladay 2 performed better for Group 2 .

\section{KEYWORDS}

High Myopia, IOL power calculation formulae, Predictability.

HOW TO CITE THIS ARTICLE: Thakur A, Saxena N, Jain AM, et al. Predictive accuracy of various IOL power calculation formulae in high axial myopia: a prospective comparative study. J. Evolution Med. Dent. Sci. 2016;5(16):813-815,

DOI: $10.14260 /$ jemds/2016/187

\section{INTRODUCTION}

With the availability of ever improving technology, better surgical skills and rising patient expectations, we cannot afford to be off the target, i.e. Target Emmetropia. We have quite a menu for IOL power calculation formulae available, but the biggest error responsible for refractive surprises is the use of ill-understood formulae. Judicious use of an appropriate formula can result in a satisfied surgeon and a gratified patient.

Prediction of Effective Lens Position (ELPo) is the biggest bottle-neck for IOL power calculation. A number of variables affect the position of IOL, thereby affecting its power. It is understood, longer the eye steeper the cornea, more is the AC depth. But now it is established that there is no linear relation between the three and such an assumption is surely going to give erroneous results. Axial length, keratometry, limbal white-white, lens thickness, geometry of the IOL (Its optics and haptics), size of the capsulorhexis are all responsible for change in ELPo.

Financial or Other, Competing Interest: None.

Submission 30-01-2016, Peer Review 10-02-2016,

Acceptance 13-02-2016, Published 25-02-2016.

Corresponding Author:

Dr. Anita Thakur,

501, Geetika Heights,

7/106, Swaroop Nagar

Kanpur-208002.

E-mail: dranita_thakur@yahoo.com

DOI: $10.14260 /$ jemds/2016/187
This directly affects the A- Constant mentioned on the box of the IOL. These constants represent the anticipated position of IOL in relation to corneal height. Thus, the power of the IOL also is relative, subject to change by so many factors. $1^{\text {st }}, 2^{\text {nd }}$ and $3^{\text {rd }}$ generation formulae are two variable formulae and they do not account for ELPo. However $3^{\text {rd }}$ generation formulae (Holladay 1, SRK/T, Hoffer Q) are the merger of linear regression analysis with the principles of theoretical eye models and allow for optimization of their constants for average AL range. ${ }^{1,2}$ But using standard optical constants often yield postoperative hyperopic errors in long eyes. ${ }^{3} 4^{\text {th }}$ generation formulae (Haigis, Holladay 2, Olsen, and Barrett Universal II) are multi variable formulae and lead to better prediction of ELPo. When fully optimized can be used for entire range of ALs. Present study was conducted to evaluate the accuracy of different formulae used for IOL power calculation in patients with high axial myopia undergoing cataract surgery.

\section{MATERIAL AND METHODS}

This prospective comparative study was conducted on 27 eyes of 22 myopic patients with axial length between 26.3 to 29.4 mm undergoing cataract surgery at a tertiary eye care facility in our centre from February 2014 to November 2015. Patients with corneal surface irregularities, glaucoma, previous ocular surgeries, combined surgical procedures and intra operative and postoperative complications were excluded. 
The eyes were divided into two groups, Group 1 with $\mathrm{AL}$ 26-28mm consisting of 23 eyes and Group 2 with AL 28-30mm consisting of four eyes. Routine preoperative ocular examination was done including Slit lamp biomicroscopy, Fundus examination, applanation Tonometry. Keratometry was done by Nidek ARK 510A, axial length was measured by optical biometry using IOL Master. Calculation of the IOL power to be implanted was done by the same person using four IOL power calculation formulae; SRK/T formula, Hoffer $Q$, Haigis formula and Holladay 2 formula.

Phacoemulsification was done through $2.8 \mathrm{~mm}$ incision by the same surgeon keeping the capsulorhexis size and surgical procedure constant. The site of the incision was selected according to the pre-operative corneal astigmatism, if present, with implantation of hydrophobic acrylic single piece foldable IOL in the capsular bag. All the patients were evaluated at 1 day, 1 week, 3 weeks and 3 months postoperatively to asses best corrected visual acuity, refraction, slit lamp biomicroscopy and fundus examination were done.

The difference in the target IOL power and postoperative refraction was estimated for all the fjour formulae. The statistical analysis of the data was performed using SPSS Software 21.0 version with $\mathrm{P}$ value $>0.05$ considered significant.

\section{RESULTS}

This study was carried out on 27 eyes of 22 patients with an AL from 26.3-29.4mm; 13 males and 9 females were part of the study with age varying from 43 to 69 years. The predominant type of cataract was early onset senile cortical cataract in sixteen eyes, five eyes showed posterior subcapsular cataract, senile nuclear sclerosis was present in six eyes. Peripheral retinal myopic degenerations were observed in 26 of the 27 eyes included in the study, while macular degeneration markedly affecting visual outcomes was seen in three eyes (Table-1).

The mean refractive error in these eyes was found to be $11.25 \pm 4.56$ with a range of -10.5 to -17 . 75. The mean $\mathrm{K}$ of the studied eyes was $(43.83 \pm 2.11)$ with a minimum of $42.13 \mathrm{D}$ and a maximum of $47.91 \mathrm{D}$. The mean axial length was $26.91 \pm 1.85 \mathrm{~mm}$ with a minimum of $26.3 \mathrm{~mm}$ and a maximum of 29.4mm. Pre-operative mean Anterior Chamber Depth (ACD) was $3.41 \pm 0.44 \mathrm{~mm}$ with a minimum of $3.21 \mathrm{~mm}$ and a maximum of $4.15 \mathrm{~mm}$ (Table 2). The predictability of power with the different formulae was assessed and is tabulated in Table 3.

\begin{tabular}{|c|c|}
\hline Age & 43 to 69 years \\
\hline Sex & 13 Males, 9 Females \\
\hline Type of cataract & PSC- 5 eyes \\
& $\begin{array}{c}\text { Presenile-16 eyes } \\
\text { Senile- } 6 \text { eyes }\end{array}$ \\
\hline Myopic Retinal Degeneration & $\begin{array}{c}\text { Central }-3 \text { eyes } \\
\text { Peripheral- } 26 \text { eyes }\end{array}$ \\
\hline \multicolumn{2}{|c|}{ Table 1: Demographic Data } \\
\hline
\end{tabular}

\begin{tabular}{|c|c|}
\hline Pre-operative Refraction & \\
Range & $-10.5 \mathrm{D}$ to $-17.75 \mathrm{D}$ \\
Mean & $-11.25 \pm 4.56 \mathrm{D}$ \\
\hline Keratometry & $42.13 \mathrm{D}-47.91 \mathrm{D}$ \\
Range & $43.83 \pm 2.11 \mathrm{D}$ \\
Mean & $26.3 \mathrm{~mm}-29.4 \mathrm{~mm}$ \\
\hline Axial Length & $26.91 \pm 1.85 \mathrm{~mm}$ \\
Range & $3.21 \mathrm{~mm}-4.15 \mathrm{~mm}$ \\
Mean & $3.41 \pm 0.44 \mathrm{~mm}$ \\
\hline ACD & Range \\
Mean & Table 2: Preoperative Patient Data \\
\hline \multicolumn{2}{|c}{} \\
\hline
\end{tabular}

\begin{tabular}{|c|c|c|c|c|}
\hline \multirow{2}{*}{ Formula } & \multicolumn{2}{|c|}{$\begin{array}{c}\text { Predictability } \\
\mathbf{1 D}\end{array}$} & $\begin{array}{c}\text { Predictability } \\
\mathbf{0 . 5} \text { D }\end{array}$ \\
\cline { 2 - 5 } & Group 1 & Group 2 & Group 1 & Group 2 \\
\hline SRK-T & $88 \%$ & $83 \%$ & $61 \%$ & $59 \%$ \\
\hline Hoffer Q & $87 \%$ & $83 \%$ & $61 \%$ & $61 \%$ \\
\hline Haigis & $88 \%$ & $84 \%$ & $69 \%$ & $70 \%$ \\
\hline Holladay 2 & $91 \%$ & $90 \%$ & $73 \%$ & $71 \%$ \\
\hline \multicolumn{2}{|c|}{ Table 3: Predictability of various Formulae } \\
\hline
\end{tabular}

\section{DISCUSSION}

$1^{\text {st }}$ and $2^{\text {nd }}$ generation IOL power calculation formulae work best for eyes with normal axial lengths. However, $3^{\text {rd }}$ generation formulae optimized separately for separate $\mathrm{AL}$ subgroups, individual surgeon and individual IOL work well for all axial lengths.

Precise power calculation in extremely long eyes has always been difficult, although SRK-T, Haigis and Holladay 2 have been recommended to offer promising predictions once optimized. In this study, we studied the refractive outcome of four different IOL power calculation formulae (SRK-T, Hoffer $Q$ Haigis and Holladay-2) in eyes with high myopia. The predictive capability within $\pm 1 \mathrm{D}$ of these formulae in Group 1 is $88 \%$ with SRK-T, $87 \%$ with Hoffer Q, $88 \%$ with Haigis and $91 \%$ with Holladay 2 and within \pm 0.5 D is $61 \%, 61 \%, 69 \%$ and $73 \%$ respectively.

There was a tendency towards resultant hyperopia. The performance of SRK-T, Hoffer Q and Haigis was comparable for target refraction of $\pm 1.0 \mathrm{D}$, whereas Haigis and Holladay 2 gave relatively better results for target refraction of $\pm 0.5 \mathrm{D}$. However in Group 2 which consisted of 4 eyes with AL between 28$30 \mathrm{~mm}$, Haigis and Holladay 2 definitely performed better.

Our results are in agreement with the study conducted by Ghanem AA, et al. ${ }^{4}$ The performance of SRK-T, Hoffer-Q, Holladay- 2 and Haigis formulas is good in low plus-powered IOLs implantation. However, a hyperopic refractive outcome is anticipated with minus power IOL implantation. Haigis formula is the best one when minus power IOL is implanted. However, in the present study Haigis and Holladay 2 faired equally well for longer ALs. Holladay and Prager. 5 have performed high resolution B scans in pseudophakic eyes and demonstrated that in longer eyes anatomy of the posterior pole may lead to unpredictable measurement of axial length. The fovea is approximately $4.5 \mathrm{~mm}$ from the centre of the optic nerve. The use of optical biometry improves the accuracy by measuring the refractive axial length to the precise point of retinal fixation rather than the anatomical axial length. 
The performance of SRK-T, Hoffer Q, Holladay 1 and Holladay 2 formulae in eyes with axial lengths longer than or equal to $27.0 \mathrm{~mm}$ was assessed by Zaldivar et al. ${ }^{6}$ It was concluded that current third- and fourth-generation lens calculation formulae have a tendency to over minus patients between -1.0 and $-4.0 \mathrm{D}$. The formulae appear to perform better for plus-power IOL implantation than for minus-power IOL implantation. Wang JK, et al. ${ }^{7}$ concluded IOL power calculated using the Haigis formula predicted the best refractive outcome in long eyes. El-Nafees R, et al. ${ }^{8}$ and Tsang $\mathrm{CS}$, et al. ${ }^{9}$ found the performance of SRK - T to give least amount of error. Petermeier and Szurman. ${ }^{10}$ studied 50 eyes with a mean AL of $32.35 \mathrm{~mm}$ (Range 29.22-36.51mm). With optimized constants, the SRK/T, Haigis, Hoffer $Q$ and Holladay 1 formulae produced small deviation of postoperative refraction from target refraction.

Terzi et al.11 studied sixty-three eyes (44 myopic, AL $\geq 26.0 \mathrm{~mm} ; 19$ hyperopic, $\mathrm{AL} \leq 22.0 \mathrm{~mm}$ ). In myopic and hyperopic RLE, optimization of lens constants improved the accuracy of IOL power calculation. Haigis. ${ }^{12,13}$ and Wang L. ${ }^{14}$ have also strongly recommended the optimization of constants.

Adi Abulafia, et al. ${ }^{15}$ compared the predicted refractions calculated using standard formulae (Holladay 1, SRK/T, Hoffer Q and Haigis) with optical IOL constants, User Group for Laser Interference Biometry constants and concluded that the SRK/T, Hoffer Q, Haigis, Barrett Universal II, Holladay 2 and Olsen methods met the benchmark criteria of having a prediction error of $\pm 0.5 \mathrm{D}$ in at least $71.0 \%$ of eyes and $\pm 1.0 \mathrm{D}$ in $93.0 \%$ of eyes with positive power IOLs $(>+6 \mathrm{D})$, whereas with low positive or negative powered IOLs Barrett Universal II formula and the Holladay 1 and Haigis formulae using the AL-adjusted method met those criteria.

To conclude, use of optical biometry optimization of the constants and intelligent use of recommended formula depending on the AL can help us achieve our goal of making cataract surgery a refractive surgery.

\section{REFERENCES}

1. Sanders DR, Retzlaff JA, Kraff MC, et al. Comparison of the SRK/T formula and other theoretical and regression formulas. J Cataract Refract Surg 1990;16:341-6.
2. Hill WE, Byrne SF. Complex axial length measurements and unusual IOL power calculations. In: Points F. Clinical Modules for Ophthalmologists. San Francisco: American Academy of Ophthalmology; 2004. p. 22-9.

3. MacLaren RE, Sagoo MS, Restore M, et al. Biometry accuracy using zero and negative-powered intraocular lenses. J Cataract Refract Surg 2005;31:280-90.

4. Asaad A Ghanem and Hosam M El-Sayed. Accuracy of intraocular lens power calculation in high myopia. Oman J Ophthalmol 2010 Sep-Dec;3(3):126-130.

5. Holladay JT, Prager TC. Accurate ultrasonic biometry in pseudophakia. Am J Ophthalmol 1989;107:189-90.

6. Zaldivar R, Shultz MC, Davidorf MJ, et al. Intraocular lens power calculations in patients with extreme myopia. J Cataract Refract Surg 2000;26:668-74.

7. Wang $\mathrm{JK}, \mathrm{Hu} \mathrm{CY}$, Chang SW. Intraocular lens power calculation using the IOLMaster and various formulas in eyes with long axial length. J Cataract Refract Surg 2008;34:262-267.

8. Raouf El-Nafees, Ashraf Moawad, Hanem Kishk, et al. Intraocular lens power calculation in patients with high axial myopia before cataract surgery. Saudi J Ophthalmol 2010 Jul; 24(3):77-80.

9. Tsang CS, Chong GS, Yiu EP, et al. Intraocular lens power calculation formulas in Chinese eyes with high axial myopia. J Cataract Refract Surg 2003 Jul;29(7):1358-64.

10. Petermeier K, Gekeler F, Messias A, et al. Intraocular lens power calculation and optimized constants for highly myopic eyes. J Cataract Refract Surg 2009;35:1575-81.

11. Terzi E, Wang L, Kohnen T. Accuracy of modern intraocular lens power calculation formulas in refractive lens exchange for high myopia and high hyperopia. J Cataract Refract Surg 2009;35:1181-9.

12. Haigis W. Intraocular lens calculation in extreme myopia. J Cataract Refract Surg 2009;35:906-11.

13. Haigis W. The Haigis formula. In: Shammas HJ, editor. Intraocular lens power calculations. Thorofare, NJ, USA: Slack Inc; 2003. p. 41-57.

14. Wang $\mathrm{L}$, et al. Optimizing intraocular lens power calculations in eyes with axial lengths above $25.0 \mathrm{~mm}$. JCRS 2011;37:2018-2027.

15. Abulafia A, Barrett GD, Rotenberg M, et al. Intraocular lens power calculation for eyes with an axial length greater than $26.0 \mathrm{~mm}$ : comparison of formulas and methods. J Cataract Refract Surg 2015 Mar;41(3):548-56. 